Bull. Chem. Soc. Ethiop. 2012, 26(2), 171-180.

Printed in Ethiopia

ISSN 1011-3924

DOI: http://dx.doi.org/10.4314/bcse.v26i2.2

(c) 2012 Chemical Society of Ethiopia

\title{
COMPARISON OF SORPTION CAPACITY AND SURFACE AREA OF ACTIVATED CARBON PREPARED FROM JATROPHA CURCAS FRUIT PERICARP AND SEED COAT
}

\author{
O.F. Okeola ${ }^{*}$, E.O. Odebunmi and O.M. Ameen
}

Department of Chemistry, University of Ilorin, Ilorin, Nigeria

(Received June 17, 2010; revised December 12, 2011)

\begin{abstract}
Activated carbons were prepared from fruit pericarp and seed coat of Jatropha curcas using $\mathrm{KOH}$ and $\mathrm{NaCl}$ as activating agents leading to the production of four samples of activated carbons JPS, JPP, JCS and JCP. The adsorption capacity based on adsorption of methylene blue was determined for each sample. A further study of adsorptive properties of the most efficient activated carbon (JPS) was made by contacting it with standard solutions of methylene blue, acetic acid and potassium permanganate. The effects of mass of active carbon used, initial concentration of the solute and the $\mathrm{pH}$ of the solution on adsorption performance were investigated. Ash content and percentage fixed carbon were determined for two of the activated carbons (JPS and JCS) with the highest adsorptive capacity. Equilibrium study on adsorption was carried out and the adsorption data were analyzed using the Langmuir isotherm. The results obtained indicate that activated carbons from the fruit pericarp and the seed coat of $J$. curcas can be used as high performance adsorbents with the fruit pericarp activated carbon showing the higher adsorption capacity. The adsorption data fitted well to the Langmuir model and adsorptive area of $824-910 \mathrm{~m}^{2} / \mathrm{g}$ was obtained for the activated carbon.
\end{abstract}

KEY WORDS: Carbonization, Adsorption, Adsorbent, Activated carbon, Jatropha curcas, Fruit pericarp, Seed coat, Chemical activation

\section{INTRODUCTION}

The process of adsorption is widely used as an effective physical method of separation in order to remove or reduce the concentration of a wide range of dissolved pollutants (organic or inorganic) in an effluent [1]. Adsorbents are applied widely in the purification of liquids and gases in the processing industries such as vegetable ghee, edible oil, sugars, pharmaceuticals, starch making and gas masking [2,3].

Activated carbon is a well known adsorbent that has been used effectively for the removal of a broad spectrum of pollutants from air, soil and liquids. Adsorption onto activated carbon has been found to be superior to other techniques because of its capability of adsorbing a broad range of different types of adsorbates efficiently and its simplicity of design [4]. Activated carbon adsorption process is used in environmental engineering practice for removal of colour, taste and odour-producing substances from natural water [5]. The process of activation is a physical change in which the adsorptive property of the primary carbon is greatly increased and improved [6]. It has been reported that activated carbon as adsorbent has many applications due to its nature and properties. A large number of materials have been used in the preparation of activated carbon, many carbonaceous materials of animal, vegetable or mineral origin can be converted into activated carbon if properly treated [7,8].

Jatropha curcas is a non-edible, oil bearing and draught hardy shrub with ecological advantages. It belongs to the Euphorbiaceae family. The Jatropha plants start yielding from the second year of planting, but in limited quantity. If managed properly, it starts giving $4-5 \mathrm{~kg}$ per tree production from the fifth year onwards and seed yield can be obtained up to 40-50 years from the day of plantation and on average the seed yield is up to 5 tons/hectare [9]. Freshly harvested Jatropha dried fruit contains about $35-40 \%$ shell and $60-65 \%$ seed (by weight). The

*Corresponding author. E-mail: Okeolaf@yahoo.com; Okeola.of@unilorin.edu.ng 
fruits are $2.5 \mathrm{~cm}$ long, ovoid, black and 2-3 halved. The plant has nearly 422 fruits per $\mathrm{kg}$ weight available for decortications of Jatropha seed for oil extraction [10].

Much has been reported about the use of the oil, cake and glycerine from the seed of the plant, but information about the use of Jatropha seed husk, which is about $39 \%$ of Jatropha seed and fruit pericarp, is very limited [10]. Related works have been published on the use of the seed coat to adsorb copper from waste water [11] and the husk as an open core gasified feedstock $[10,12]$. The present investigation was under taken to prepare activated carbons from the fruit pericarp and seed coat of J. curcas. It has been observed that adsorption capacity of activated carbon is best assessed from aqueous solution of the desired solute [1], thus the study involved the conversion of the fruit pericarp and seed coat into activated carbon and determining its adsorption capacity from aqueous solution on three solutes; methylene blue, acetic acid and potassium permanganate, (high and low molecular weight organic and inorganic compounds, respectively).

\section{EXPERIMENTAL}

The Jatropha fruit was collected in different locations in Ilorin metropolis, Nigeria. The fruit was dried and the pericarp removed to free the seed, the seed was further dried and dehulled, i.e. the seed coat was removed. The fruit pericarp and the seed coat were used for this investigation.

The chemicals used including potassium hydroxide, sodium chloride, acetic acid, methylene blue and potassium permanganate were of analytical grade and used after further purification where necessary. Stock solutions were prepared by dissolving predetermined amount of the reagent in distilled water. The test solutions of desired concentration were then prepared by diluting the stock solution. The $\mathrm{pH}$ of the solution was adjusted to the required value with $0.1 \mathrm{M}$ $\mathrm{HCl}$ and $0.1 \mathrm{M} \mathrm{NaOH}$ solutions.

\section{Carbonization and activation}

The activated carbon was obtained by chemical activation method as it has been observed to produce better results [13]. This was carried out by washing the Jatropha fruit pericarp and seed coat with distilled water, sun dried and oven dried at $105^{\circ} \mathrm{C}$ for $1 \mathrm{~h}$. The process of converting to carbon was carried out by burning in a limited air supply in a burning chamber which allowed thin cloud of gases and volatile products to ooze out. The charred product was allowed to cool to room temperature, ground to workable particle size and sieved with a laboratory sieve (75 $\mathrm{mm}$ mesh sieve). The sample was then purified with $0.5-1.0 \mathrm{M} \mathrm{HCl}$ solution, rinsed with water and dried in an oven at $100{ }^{\circ} \mathrm{C}$ for $45 \mathrm{~min}$. The percentage yield of carbonized product was determined from the difference in the weight of the raw sample and the carbonized sample.

Activation was carried out in a muffle furnace using $\mathrm{KOH}$ and $\mathrm{NaCl}$ separately as activating reagents. The sample was mixed with $0.5-1.0 \mathrm{M}$ solution of the activating agents, stirred and heated until paste formation. This was placed in a muffle furnace at $450{ }^{\circ} \mathrm{C}$ for $3 \mathrm{~h}$, allowed to cool to room temperature, washed with water and dried at $120{ }^{\circ} \mathrm{C}$ for $30 \mathrm{~min}$. The resulting activated carbon was ground and sieved with $185 \mu \mathrm{m}$ mesh size sieve and kept in a desiccator.

The percentage ash content was determined by placing a known weight of active carbon in a crucible and igniting it in the furnace. The loss in weight was thus calculated.

\section{Adsorption study}

The adsorption potentials of the carbonized seed coat and pericarp were determined following the reported methods of Odebunmi and Okeola and Nameni et al. [3, 14]. In this method batch sorption experiments were carried out at room temperature on a mechanical shaker. Working solutions of the solutes; methylene blue (MB), acetic acid (AA) and potassium permanganate 
(PP) were prepared from stock solutions, a known amount of activated sample was added to each of the solutions of the solutes in a conical flask, thoroughly mixed and shaken for $1 \mathrm{~h}$. The mixture was filtered and the post adsorption concentration of the adsorbate solution was determined in the filtrate using spectrophotometric technique for methylene blue and potassium permanganate solutions $[15,16]$. Titration with standard solution of sodium hydroxide was used in the determination of concentration of acetic acid, [17].

Adsorption isotherm study of active carbon was determined using $0.1-0.55 \mathrm{~g}$ of the carbon and $100 \mathrm{~mL}$ of $250 \mathrm{mg} / \mathrm{L}$ of methylene blue, while $5.0 \mathrm{~g}$ of activated carbon was used for various solutions of acetic acid of different concentration 1-10 M. The effect of initial concentration of solute on adsorption was determined by preparing solutions of different concentrations of each solute, acetic acid, methylene blue and potassium permanganate separately. Adsorption of the solute was measured using a fixed quantity of the activated carbon, fixed contact period and at room temperature.

In order to investigate the effect of mass of adsorbent on the adsorption of solute a series of adsorption experiments was carried out with different adsorbent dosage $(0.1-1.0 \mathrm{~g})$ and a fixed initial concentration $(0.35 \mathrm{M})$ of the solute. In each case the quantity and percentage of adsorbate removed was determined following the methods of Nameni et al. and Omomnhenle et al. $[13,18]$ using the following equation:

Adsorbate removed $\mathrm{mg} / \mathrm{g}=\left(\mathrm{C}_{\mathrm{i}}-\mathrm{C}_{\mathrm{f}}\right) \mathrm{V} / \mathrm{m}$

$\%$ adsorbate removed $=\left(\mathrm{C}_{\mathrm{i}}-\mathrm{C}_{\mathrm{f}}\right) \div \mathrm{C}_{\mathrm{i}} \mathrm{x} 100$

where $\mathrm{C}_{\mathrm{i}}$ and $\mathrm{C}_{\mathrm{f}}$ are pre and post adsorption concentration $(\mathrm{M})$, respectively and $\mathrm{V}=$ volume of adsorbate solution (L).

The effect of $\mathrm{pH}$ on the adsorption capacity was analyzed over $\mathrm{pH} 4-12$ while maintaining a constant mass of activated carbon in the same standard solution of MB.

\section{Adsorption isotherm}

The adsorption capacity was determined using the Langmuir adsorption isotherm for modelling the adsorption data. The isotherm had been used to determine the adsorption capacity of activated carbon prepared from samples of coconut shell, maize cob, orange peels, and guinea corn stem as well as used tyre by Odebunmi and Okeola [3] and water hyacinth ash by Uddin $e t$ al. [19]. The isotherm model equation is:

$$
\frac{1}{x}=\frac{1}{x_{m}}+\frac{1}{K x_{m}} \cdot \frac{1}{c}
$$

where $X=$ amount of solute adsorbed per unit mass of adsorbent, $X_{m}=$ limiting amount of adsorbate that can be taken up (i.e. monolayer coverage), $\mathrm{C}=$ equilibrium concentration (M) of the adsorbate (the solute), $\mathrm{K}=$ adsorption equilibrium constant (related to the temperature and nature of the materials in the system.

Adsorption isotherm studies were thus determined with the different mass of activated carbon in various solutions of the same concentration of methylene blue, while a fixed mass of $5 \mathrm{~g}$ of activated carbon was added to various solutions of acetic acid of different concentration. The mixture in each case was agitated with HY-2 orbital shaker at $250 \mathrm{rpm}$ for $1 \mathrm{~h}$. In each case the mixture was filtered and post adsorption equilibrium concentration was determined from the filtrate. 21].

The specific area of the activated carbon was estimated using the following equation [20, 


$$
\mathrm{S}=\left(\mathrm{X}_{\mathrm{m}} \times \mathrm{N}_{\mathrm{A}} \times \mathrm{a}\right) / \mathrm{MW}
$$

where $\mathrm{S}\left(\mathrm{m}^{2} / \mathrm{g}\right)=$ specific surface area of the adsorbent, $\mathrm{X}_{\mathrm{m}}=$ maximum monolayer desorption (Langmuir constant), $\mathrm{N}=$ Avogadro's number, and $\mathrm{a}=$ area of the adsorbing molecule.

\section{RESULTS AND DISCUSSION}

Adsorption capacity of the activated carbon prepared from Jatropha curcas seed coat and fruit pericarp

The adsorption of the dye, methylene blue, cationic in nature was used for comparative study of the sample of active carbons produced, under the same conditions of amount of adsorbent, contact time, temperature and $\mathrm{pH}$. The results presented in Table 1 show that the activated carbon from Jatropha fruit pericarp activated with $\mathrm{NaCl}$ (JPS) has the highest adsorption capacity of $92.4 \%$, while Jatropha seed coat KOH activated sample (JCP) with adsorption capacity of $74.3 \%$ was the least in the set. Others include Jatropha fruit pericarp activated with $\mathrm{KOH}$ (JPP) $88.5 \%$ and Jatropha fruit coat activated with $\mathrm{NaCl}$ (JCS) $88.9 \%$. Thus the adsorptive capacities of the active carbons from the parts of the Jatropha plant compare quantitatively with published result of activated carbon from some Tanzanian carbonaceous agrowastes [7]. The results are also in agreement with various similar works on adsorption potential and capability of fruit and seed wastes made activated carbons, i.e. shells from palm kernel, Cinnariumschwein furthi nut and coconut [8, 18, 22]. All the samples of activated carbon in the present study were able to decolourise standard solutions of methylene blue to various extents.

Table 1. Adsorption capacity, yield of carbonization, ash and fixed carbon contents of the activated carbon prepared from Jatropha curcas seed coat and fruit pericarp.

\begin{tabular}{|l|c|c|c|c|c|c|}
\hline $\begin{array}{l}\text { Active } \\
\text { carbon } \\
\text { source }\end{array}$ & $\begin{array}{c}\text { Activating } \\
\text { agent }\end{array}$ & $\begin{array}{c}\text { Sample } \\
\text { code }\end{array}$ & $\begin{array}{c}\text { Adsorption } \\
\text { capacity (\%) }\end{array}$ & $\begin{array}{c}\text { Yield of } \\
\text { carbonized } \\
\text { product }\end{array}$ & $\begin{array}{c}\text { Ash } \\
\text { content (\%) }\end{array}$ & $\begin{array}{c}\text { Fixed } \\
\text { carbon (\%) }\end{array}$ \\
\hline \multirow{2}{*}{ Fruit pericarp } & $\mathrm{NaCl}$ & JPS & 92.4 & 39.8 & 34.8 & 65.7 \\
\cline { 2 - 7 } & $\mathrm{KOH}$ & $\mathrm{JPP}$ & 88.5 & 39.8 & $\mathrm{ND}$ & $\mathrm{ND}$ \\
\hline \multirow{2}{*}{ Seed coat } & $\mathrm{NaCl}$ & $\mathrm{JCS}$ & 88.9 & 35.7 & 25.6 & 74.4 \\
\cline { 2 - 7 } & $\mathrm{KOH}$ & $\mathrm{JCP}$ & 74.3 & 35.7 & $\mathrm{ND}$ & $\mathrm{ND}$ \\
\hline
\end{tabular}

$\mathrm{ND}=$ not determined

\section{Ash, fixed carbon and the yield of carbonization}

The yield of carbonized products, ash and fixed carbon contents for a particular activated carbon are factors which could influence the decolourising (adsorption) power of the activated carbon [23]. Table 1a presents the yield of carbonized products from the raw samples of the fruit pericarp and the seed coat. From the data, the carbonized yield of Jatropha fruit pericarp $(39.8 \%)$ is higher than Jatropha seed coat (35.7\%). Table 1 also contained the percentage ash and fixed carbon for the activated carbon from Jatropha fruit pericarp activated with $\mathrm{NaCl}$ (JPS) the result is $34.3 \%$ and $65.6 \%$, respectively, while the activated carbons from Jatropha seed coat also activated with $\mathrm{NaCl}$ (JCS) has $25.3 \%$ and $74.7 \%$, respectively. The ash content is a measure of the inorganic content in the sample, the results compare favourably with the report of Odebunmi and Okeola [3], as well as Adediran and Nwosu [24]. Although the activated carbon from pericarp has lower fixed carbon than that for its seed coat, the unexpected higher 
adsorptive capacity could be the effect of the activating agent, Table $1 \mathrm{a}$, which means that the carbon content was well activated $[3,7]$.

\section{Effect of nature of adsorbates}

Different adsorbates and adsorbents exhibit different types of equilibrium relationship where quantity adsorbed is a function of final and equilibrium concentration [25]. The effect of nature of solute material on the adsorption capacities is presented in Table 2. Activated carbon produced from fruit pericarp and activated with $\mathrm{NaCl}$ (i.e. JPS) was used for this purpose. The same mass of the JPS was made to adsorb from each of the solution of MB, AA and PP of the same concentration, within the same contact time and at the same temperature $\left(27^{\circ} \mathrm{C}\right)$. The percentage of the solute removed was found to be in the following decreasing order of $\mathrm{MB}>$ AA $>\mathrm{KMnO}_{4}$ (Table 2). The order of this adsorption has been explained in literature as being due to the fact that activated carbon has greater affinity for organic adsorbates and usually, the higher the molecular weight of the adsorbate the greater the adsorption $[3,26]$. Similarly, it has been reported that high molecular weight and low solubility are factors that influence the performance of activated carbons in water [5].

Table 2. Effect of nature of solute on adsorption on JPS at $27^{\circ} \mathrm{C}$.

\begin{tabular}{|l|l|}
\hline Solute & $\%$ of the solute removed \\
\hline Acetic acid & 79.1 \\
\hline Methylene blue & 86.2 \\
\hline Potassium permanganate & 62.8 \\
\hline
\end{tabular}

\section{Effect of the quantity of adsorbent on adsorption}

The quantity or mass of adsorbent is an important factor in large scale industrial application of adsorbent in the removal of a desired solute. In order to investigate the effect of mass of adsorbent on the adsorption, a series of adsorption experiments were carried out with different masses of adsorbent at fixed initial solute concentration. The effect of adsorbent mass was determined on the adsorption of methylene blue (MB), acetic acid (AA), and potassium permanganate (PP) by JPS activated carbon. Figure 1 shows the amount of each solute adsorbed with varying amounts of activated carbon JPS. The results in each case indicate that solute removal efficiency increased with increase in mass of adsorbent. The increase in adsorbent mass increases the contact surface of adsorbent particles which means that it will be more probable for solute molecules to be adsorbed on adsorption sites, and thus adsorption efficiency is increased [14]. However the removal increases up to certain limit and then remains constant, the limit in each case is still related to effect of adsorbate on adsorption.

\section{Effect initial concentration of solute}

The effect of initial concentration of solute on adsorption process was carried out with adsorption of acetic acid (AA), methylene blue (MB) and potassium permaganate (PP) by JPS activated carbon. The results presented in Figure 2 show that for potassium permanganate and acetic acid, solute removal efficiency decreased with increase initial concentration. This is as a result of the fact that at lower concentration, the ratio of amount of solute (adsorbate) available to the available surface area of adsorbent that is adsorption sites is low and subsequently a higher percent of adsorption resulted. At higher initial concentration, there was lower adsorption yield which is due to increase in the ratio because the adsorption sites become fewer compared 
to the amount of solute available [27]. In the same vein the results compared favourably with other reports in which it was ascertained that at higher concentration, lower adsorption yield is due to the saturation of adsorption site [14, 28], however, as Figure 2 shows that MB removal increased initially with increase in initial concentration of solute and then started to decrease with further increase in solute concentration. A similar observation was made in the adsorption of acid green dye, and this was explained as due to all mass transfer resistance of the dye between the aqueous and solid phases [27].

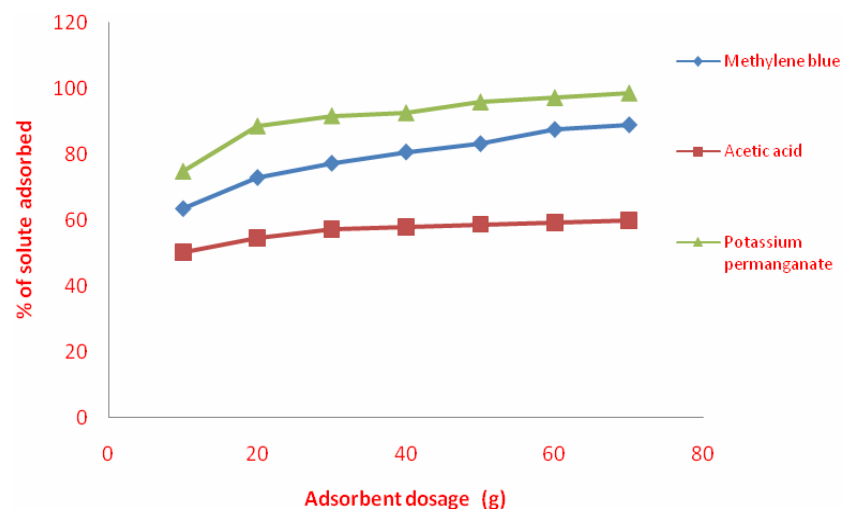

Figure 1. Effect of adsorbent dose on adsorbent.

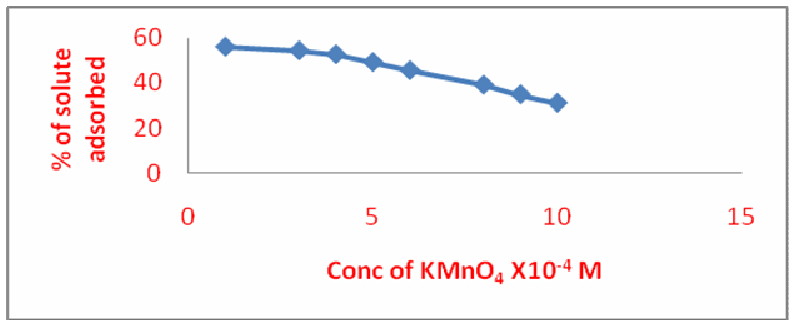

Figure 2a. Effect of initial concentration of $\mathrm{KMnO}_{4}$ on the adsorption.

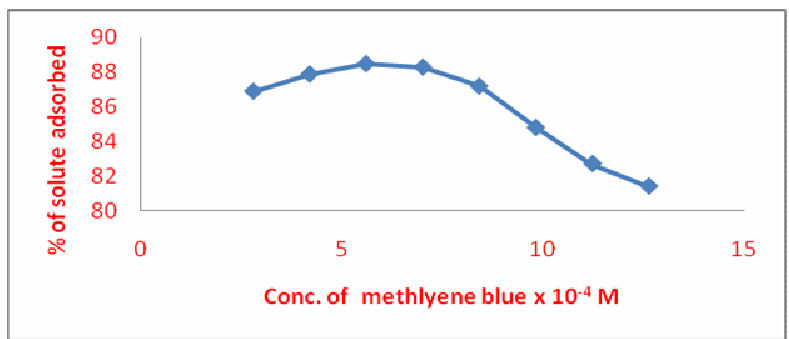

Figure $2 b$. Effect of initial concentration of methylene blue on the adsorption.

Bull. Chem. Soc. Ethiop. 2012, 26(2) 


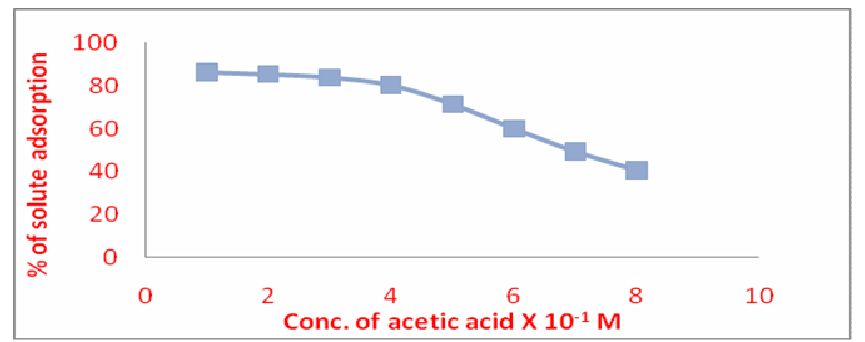

Figure 2c. Effect of initial concentration of the acetic acid on the adsorption.

\section{Effect of $p H$ on $M B$ adsorption}

The adsorption of MB by the activated carbon was found to be affected by $\mathrm{pH}$ of the solution as shown in Figure 3. From the figure it is clearly shown that larger quantities of MB were adsorbed at higher $\mathrm{pH}$. The quantity of $\mathrm{MB}$ adsorbed was found to be low at low $\mathrm{pH}$, the increase in adsorption of $\mathrm{MB}$ (a cationic dye) with increase in $\mathrm{pH}$ may be related to the magnitude of negative charge on the surfaces of the dye as the $\mathrm{pH}$ increases as well as functional group of the dye [18].

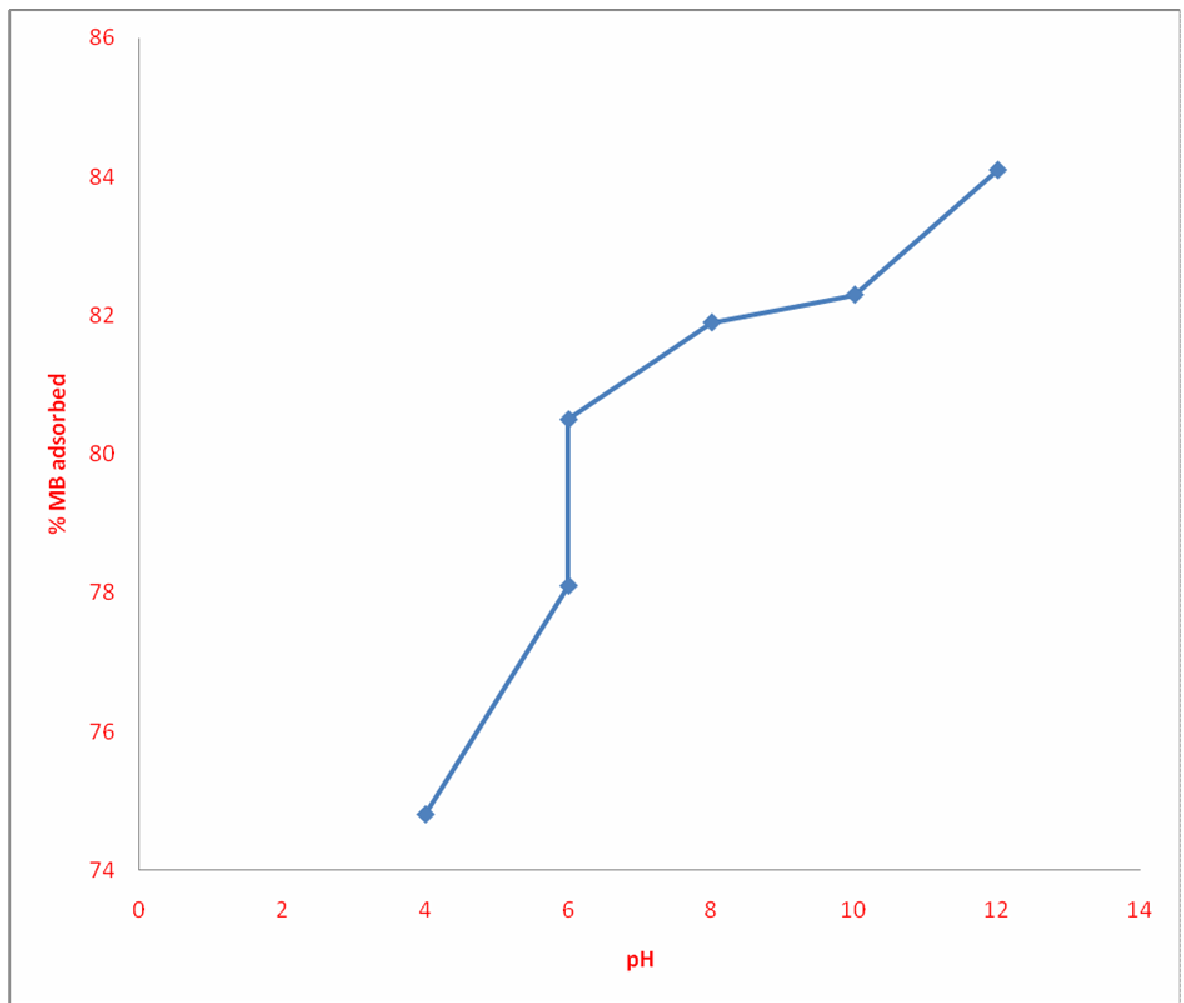

Figure 3. Effect of $\mathrm{pH}$ on the adsorption of methylene blue.

Bull. Chem. Soc. Ethiop. 2012, 26(2) 
Adsorption isotherm

Equilibrium study of adsorption provides information on the capacity of the adsorbent. An adsorption isotherm is characterized by certain constant values which express the surface properties and affinity of the adsorbent and can also be used to compare the adsorptive capacities of the adsorbent for different solute [19].

The adsorption isotherm shows the distribution of adsorbed molecules between the adsorbent and the liquid phase when the adsorption process reaches an equilibrium state, which provide basis for the designed adsorption system [29]. Analysis of isotherm data by fitting them to different isotherm models is an important step to find the suitable model that can be used for design purpose [4].

The adsorption data of activated carbon prepared from the pericarp and with sodium chloride activation (JPS) for adsorption of MB and AA were used in linear plots (Figures 4 and 5). The linear plots for the two sets of data presented in Figure 4 and 5 showed that the two set of data are well fitted to Langmuir isotherm, with the correlation coefficient values of 0.995 and 0.991 for acetic acid and methylene blue adsorption respectively. The adsorption Langmuir equilibrium constants and estimated surface area based on AA and MB onto Jatropha fruit pericarp sodium chloride activated carbon (JPS) are presented in Table 3. The specific surface area of monolayer coverage was determined from the value of $\mathrm{X}_{\mathrm{m}}$ based on the published reports $[20,21]$. From Table $3, X_{m}$ for AA and MB adsorption were $71.4 \mathrm{mg} / \mathrm{g}$ and $87.7 \mathrm{mg} / \mathrm{g}$, respectively. Also the specific surface areas estimated for the activated carbons were 902 and $824 \mathrm{~m}^{2} / \mathrm{g}$ based on the molecule of AA and MB, respectively (Equation 4).

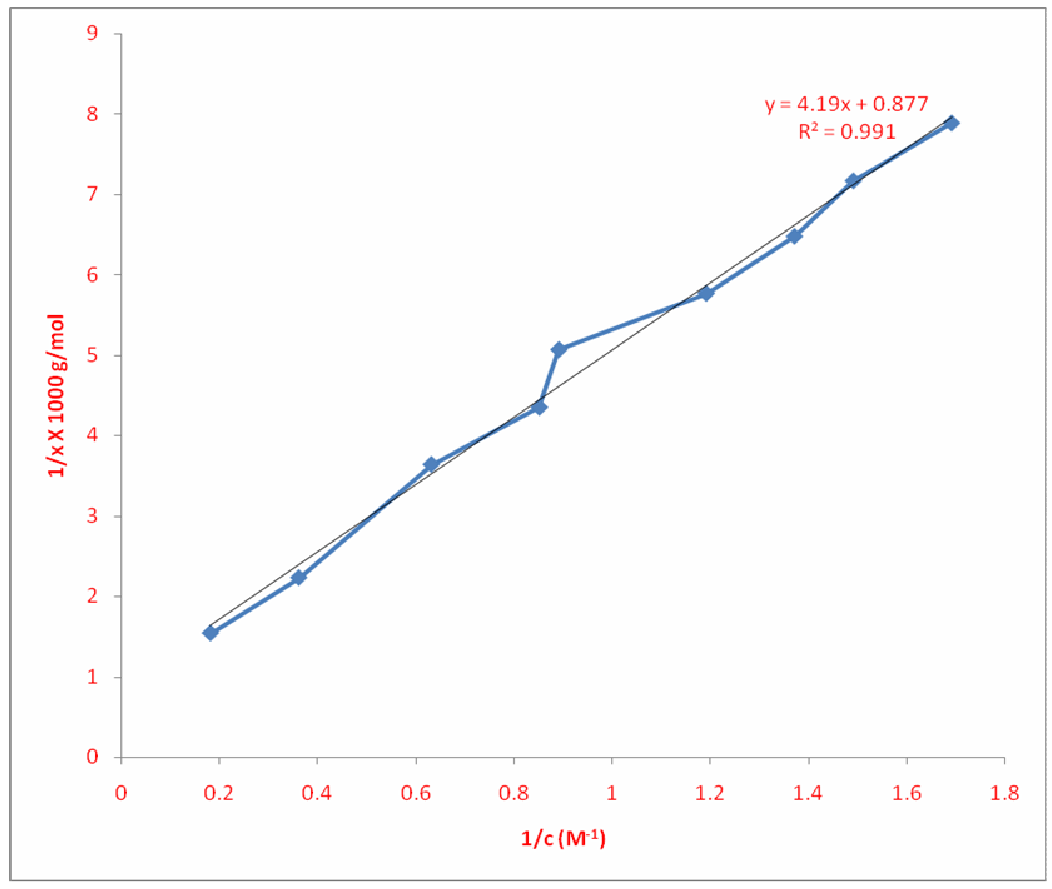

Figure 4. Langmuir isotherm of plot of adsorption of MB on active carbon JPS. 


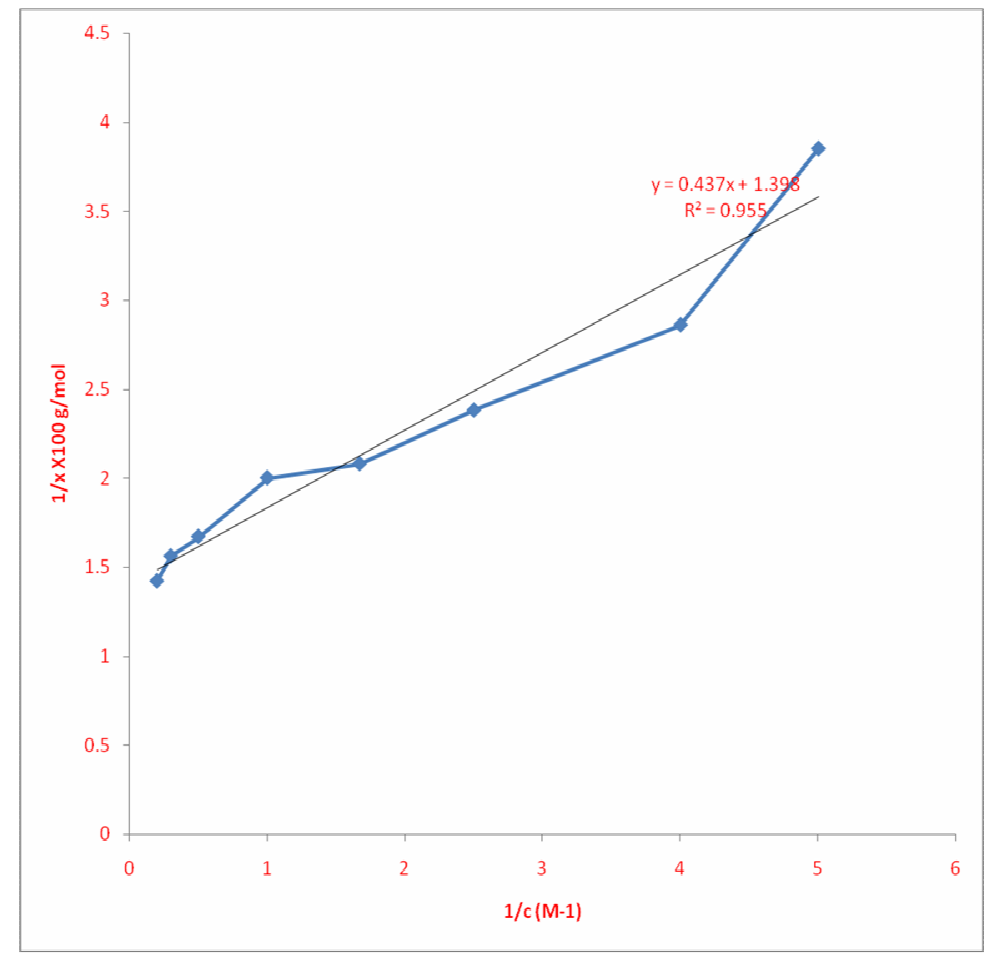

Figure 5. Langmuir isotherm of plot of adsorption of acetic acid on active carbon JPS.

Table 2. Langmuir constants and estimated surface area for adsorption of methylene blue and acetic acid adsorption on Jatropha curcas activated charcoal (JPS).

\begin{tabular}{|l|l|l|l|l|}
\hline Solute & $\mathrm{K}_{\mathrm{L}}(\mathrm{l} / \mathrm{mg})$ & $\mathrm{X}_{\mathrm{m}}(\mathrm{mg} / \mathrm{g})$ & $\mathrm{R}^{2}$ & Estimated surface area $\mathrm{m}^{2} / \mathrm{g}$ \\
\hline MB & 0.201 & 87.7 & 0.991 & 824 \\
\hline AA & 3.21 & 71.4 & 0.995 & 902 \\
\hline
\end{tabular}

The observed surface area based on MB adsorption is within the range of $600-1000 \mathrm{~m}^{2} / \mathrm{g}$ obtained from activated carbons from similar and related raw materials based on MB adsorption $[3,7]$.

\section{CONCLUSIONS}

The use of Jatropha curcas fruit pericarp and seed coat as raw material for preparation of activated carbon has been examined and the results showed that activated carbon made from both parts of this crop can be used as an effective adsorbent. The pericarp activated carbon sample on further examination was found to be an effective adsorbent for organic and inorganic solutes from aqueous solution. The activated carbon prepared from the $J$. curcas pericarp and activated with $\mathrm{NaCl}$ (JPS) was examined for various adsorption conditions and it was found that adsorption is more effective at a lower solute concentration and large quantity of activated carbon dosage. Equilibrium adsorption data fitted well with the Langmuir isotherm equation and enabled the determination of the monolayer adsorption capacities of methylene blue (MB) and

Bull. Chem. Soc. Ethiop. 2012, 26(2) 
acetic acid (AA) (organic species of high and lower molecular weight, respectively). The specific surface area estimated for the activated carbons was found to be comparable to be related values obtained for similar raw materials using methylene blue as a means of surface area estimation. Therefore, activated carbon from J. curcas can thus be applied for the removal inorganic and especially organic substances from water and effluents by adsorption process.

\section{REFERENCES}

1. Mohammed-Khah, H.; Ansari, R. Int. J. Chem. Tech. Res. 2009, 1, 859.

2. Dabrowski, A. Adv. Colloid Interf. Sci. 2001, 93, 135.

3. Odebunmi, E.O.; Okeola, O.F. J. Chem. Soc. Nig. 2001, 26, 149.

4. Nwabanne, J.T.; Igbokwe, P.K. J. Eng. Appl. Sci. (JEAS) 2008, 3, 829.

5. Lenntech: Adsorption / Active Carbon, http://www.lenntech.com/feedback_uk.htm, Retrieved on $30-4-2009$.

6. Oyok, K.B.; Igbokwe, P.K. J. Chem. Soc. Nig. 2001, 26, 91.

7. Mkayula, L.L.; Matunbo, M.A. Bull. Chem. Soc. Ethiop. 1994, 8, 25.

8. Ochonorgor, A.E.; Ejikemi, P.M. J. Chem. Soc. Nig. 2005, 30, 91.

9. Kumar, S.; Gupta, A.K.; Naik, S.N. J. Sci. Ind. Res. 2003, 62, 24.

10. Vyas, D.K.; Singh, R.N. Renewable Energy 2007, 32, 512.

11. Jain, N.; Josh, H.C.; Dutta, C.; Kumar, S.; Pathak, H. J. Sci. Ind. Res. 2008, 67, 154.

12. Singh, R.N.; Vyas, D.K.; Srivastava, N.S.L.; Narra, M. Renewable Energy 2008, 33, 1868.

13. Ajayi, O.A.; Olawale, A.S. J. Appl. Sci. Res. 2009, 5, 2148.

14. Nameni, M.; Moghadam, A.R.M.; Arami, M. Int. J. Environ. Sci. Tech. 2008, 5, 161.

15. Babarinde, A.N.; Oyebamiji, J.B.; Kehinde A.A. J. Appl. Sci. Res. 2008, 4, 1420.

16. Gueu, S.; Yao, B.; Adouby, R.; Ado, G. Int. J. Environ. Sci. Tech. 2007, 4, 11.

17. Oremusova, J. Manual for Laboratory Practical in Physical Chemistry for Students of Pharmacy, Department of Physical Chemistry, Faculty of Pharmacy, Comenias University, Brassiolaria, Slovia; 2007.

18. Omomnhenle, S.I.; Ofomaja, A.E.; Okiemen, F.E. J. Chem. Soc. Nig. 2006, 31, 161.

19. Uddin, M.T.; Islam, M.S.; Abedin, M.Z. J. Eng. Appl. Sci. (JEAS) 2007, 2, 121.

20. Dunicz, B.L. J. Chem. Educ. 1961, 38, 358.

21. Potgieter, J.H. J. Chem. Educ. 1991, 68, 340.

22. Gimba, C.E.; Olayemi, J.Y.; Ifije, D.O.H. Kagbu, J.A. J. Chem. Soc. Nig. 2001, 36, 23.

23. Ogbonnaya, O. J. Chem. Soc. Nig. 1992, 17, 11.

24. Adediran, G.O.; Nwosu, F.O. J. Chem. Soc. Nig. 1996, $21,28$.

25. Ahmad, A.A.; Hameed, B.H.; Azeez, N. J. Harzard. Mater. 2006, 10, 1.

26. Schulinger, M.T.; Erskine, B.H. Chem. Eng. Prog. 1971, 67, 41.

27. Ramamurthi, V.; Jaikumar, V. Int. J. Chem. 2009, 1, 2.

28. Tiwari, R.P.; Ramudu, B.P.; Srivastava, R.K.; Gupta, M.K. Iranian J. Environ. Health Sci. Eng. 2007, 4, 139.

29. Hammeed, B.H.; Din, A.T.M.; Ahmad A.L. J. Hazard. Mater. 2006, 10, 1. 